\title{
Serotonergic Afferents to the Rat Olfactory Bulb: I. Origins and Laminar Specificity of Serotonergic Inputs in the Adult Rat
}

\author{
John H. McLean' and Michael T. Shipley ${ }^{1,2}$ \\ 'Department of Anatomy and Cell Biology, Division of Neurobiology, and 'Department of Neurosurgery, University of \\ Cincinnati College of Medicine, Cincinnati, Ohio 45267
}

This is a study of the chemoanatomical organization of the projection from the raphe nuclei to the main olfactory bulb in the rat. A heavy projection from the dorsal and median raphe nuclei to the main olfactory bulb was shown by both retrograde and anterograde tracing techniques. Following injections of $1 \%$ wheat germ agglutinin-horseradish peroxidase (WGA-HRP) into the main olfactory bulb, up to 1300 neurons were retrogradely labeled in the dorsal and median raphe nuclei, a much larger number than has been suggested by previous studies. By combining 5-HT immunofluorescence with True blue retrograde fluorescent labeling, it was determined that the vast majority of raphe neurons that project to the olfactory bulb contain serotonin.

Injections of WGA-HRP into dorsal and/or median raphe produced dense anterograde labeling in the glomeruli, while fewer labeled fibers were observed in the external plexiform layer, internal plexiform layer, and granule cell layer. In contrast to the number of other centrifugal afferents to the bulb, a significant contingent of fibers from the raphe nuclei enters the main olfactory bulb (MOB) from outside in, i.e., via the olfactory nerve layer. Serotonergic fibers in MOB were visualized by immunocytochemistry, and the distribution of specific 5-HT fibers closely matched the distribution of anterograde terminal label resulting from injections of WGAHRP in the raphe nuclei. The serotonergic fibers have a specific laminar distribution and morphology in MOB. Thus, the density of the serotonergic innervation to the glomerular layer is 2-3 times that of any other layer in MOB. In addition to their preferential innervation of the glomeruli, glomerular and infraglomerular serotonergic fibers are morphologically different. Serotonergic fibers located in the glomerular layer are generally thick $(0.25-0.60 \mu \mathrm{m})$ compared to the thinner $(0.25-0.35 \mu \mathrm{m})$ fibers that predominate in infraglomerular layers. Another difference is that the glomerular fibers often contain varicosities that are greater than $1 \mu \mathrm{m}$ in diameter, while varicosities along infraglomerular fibers are usually barely larger than the axonal diameter. Finally, glomerular

\footnotetext{
Received July 25, 1986; revised Mar. 27, 1987; accepted Apr. 1, 1987

We wish to thank Dr. Beata Frydel, Mrs. Karen Wilburn, and Ms. Nancy Rosen for technical assistance, and Ms. Rose McCormick for preparing the manuscript. We are also grateful to Ms. Sheryl Schumacher for helping with some of the initial WGA-HRP tracing experiments; Louis Amezaga for dorsal raphe lesion studies; and Peter Hug and Jesus Luna for writing programs for our computerized image analysis. This work was supported by grants from the NIH (NS 23348) and U.S. Army (DAMD17-86-C-6005).

Correspondence should be addressed to Dr. Michael T. Shipley, Department of Anatomy and Cell Biology, Division of Neurobiology, University of Cincinnati College of Medicine, Cincinnati, $\mathrm{OH} 45267-0521$.

Copyright (C) 1987 Society for Neuroscience 0270-6474/87/103016-13\$02.00/0
}

fibers are much more intensely stained than infraglomerular fibers. Electrolytic lesions of the dorsal and median raphe caused a total depletion of serotonin fiber staining in the bulb, demonstrating that the raphe nuclei are the sole source of the serotonergic input to the main olfactory bulb.

Thus, it has been demonstrated that serotonergic neurons in dorsal and median raphe project very heavily to glomeruli and less heavily to other layers in the main olfactory bulb. The dense glomerular projection of raphe neurons suggests that this predominantly serotonergic system can significantly influence neural activity at the initial level of synaptic integration in the olfactory system.

The raphe nuclei contain serotonergic (5-HT) neurons that project widely throughout the CNS. The ubiquitous distribution of raphe projection fibers suggests that serotonergic neurons are involved in one or more generalized functions in the brain. A major obstacle to understanding the functional significance of raphe 5-HT neurons is the lack of knowledge of their precise postsynaptic targets. This is particularly true for the serotonergic projection to the cerebral cortex, where, in the rat, the fibers appear to terminate in all cortical layers to some degree, although in some cortical fields some laminae are more densely innervated than in others (Lidov et al., 1980). Even in the primate, where there is more laminar preferentiality of 5-HT termination (Kosofsky et al., 1984), it is still difficult to speculate which, of the many diverse cortical cell types, might be the targets of serotonergic synapses.

The cortex of the main olfactory bulb (MOB) in the rat contains 6 distinct and relatively simple layers. The cell types and physiological characteristics of the main circuit elements of $\mathrm{MOB}$ are well established (Shepherd, 1983). MOB is, thus, a potentially useful system in which to study the organization of serotonergic afferents to a cortical target structure. Previous investigators have reported projections to $\mathrm{MOB}$ from the raphe nuclei. These reports generally agree that a few neurons in the dorsal and median raphe nuclei project to MOB (Broadwell and Jacobowitz, 1976; Davis et al., 1978; deOlmos et al., 1978; Araneda et al., 1980, 1981; Guevara-Aguilar et al., 1982). Many raphe neurons are serotonergic (Steinbusch and Nieuwenhuys, 1983) and serotonergic fibers, presumably from the raphe nuclei, have been observed in MOB (Steinbusch, 1981; Takeuchi et al, 1982). However, to date, the extent of the raphe projection to MOB has been underestimated, except in recent studies in the mouse (Carsen, 1984; Shipley and Adamek, 1984), and the organization of raphe terminal arborizations in MOB and their relationship to the distribution of 5-HT-immunoreactive fibers have not been thoroughly examined. 
In the present investigation, anterograde and retrograde tracing methods and immunocytochemistry have been used in conjunction with image analysis/enhancement techniques to study the detailed organization of the raphe serotonergic projection to the rat olfactory bulb. The results demonstrate that the raphe serotonergic projections to the bulb are strong, organized, and preferentially focused on neural targets involved in the first layer of synaptic integration in the olfactory bulb.

\section{Materials and Methods}

Adult male Sprague-Dawley rats $(300-350 \mathrm{gm})$ were used in all experiments. For surgery, the animals were anesthetized with sodium pentobarbital $(40 \mathrm{mg} / \mathrm{kg})$.

\section{Wheat germ agglutinin-horseradish peroxidase (WGA-HRP) tracing}

In separate experiments, WGA-HRP was used as either a retrograde or an anterograde tracer.

Retrograde study. Retrograde labeling with WGA-HRP was used to determine the number and distribution of neurons in the raphe nuclei that project to MOB.

In different experiments, multiple injections totaling $50-300 \mathrm{nl}$ of $1 \%$ WG $\Lambda$-HRP were placed in the MOB, using a glass micropipette and a positive pressure hydraulic injection system (Shipley, 1982a).

Anterograde study. WGA-HRP was also used to determine the axonal trajectories and termination sites of raphe projections to MOB. A glass pipette containing $1 \%$ WGA-HRP was advanced stereotaxically to the dorsal and/or median raphe nuclei. The stereotaxic coordinates, using the atlas of Paxinos and Watson (1982), were as follows: AP, -7.0 to $-8.0 \mathrm{~mm} ; \mathrm{L}, 0.0 \mathrm{~mm} ; \mathrm{H}, 6.0-8.0 \mathrm{~mm}$. Twenty-five to forty nanoliters of $1 \%$ WGA-HRP were injected into the raphe in each experiment. In some animals 2 injections were made, one aimed at the dorsal and the other at the median raphe, in an attempt to visualize the full extent of the raphe MOB projection. In a few instances, the injection sites somewhat exceeded the boundaries of the dorsal and median raphe, but this posed no problem of interpretation because no other brain stem neurons project to the bulb save those in locus coeruleus (deOlmos et al., 1978; Davis and Macrides, 1983; Shipley et al., 1985; and the present study), which was not involved in any of the injections. Moreover, the patterns of anterograde labeling in MOB that were oblained with the larger injections were identical to those obtained with smaller injections confined to the raphe, except that the larger injections resulted in denser labeling.

\section{WGA-HRP tissue processing}

Following a survival time of $1 \mathrm{~d}$, the rats were deeply anesthetized with sodium pentobarbital and perfused transcardially with $0.9 \%$ saline containing $1 \%$ dimethyl sulfoxide until the perfusate cleared, which was followed by perfusion with a $0.1 \mathrm{M}$ phosphate-buffered (pH 7.4) fixative ( $1.0 \%$ glutaraldehyde, $1.25 \%$ paraformaldehyde) for $30 \mathrm{~min}$. Perfusion with fixative was immediately followed by perfusion with cold phosphate buffer containing $10 \%$ sucrose for an additional $30 \mathrm{~min}$. The brain was removed from the skull and placed overnight in cold phosphate buffer containing $20 \%$ sucrose. Frozen sections 40 or $50 \mu \mathrm{m}$ thick were cut in the transverse or sagittal plane and reacted for HRP histochemistry using the tetramethyl benzidine (TMB) protocol (Mesulam, 1978) with modifications (Shipley, 1982b). Estimates of numbers of raphe neurons projecting to MOB were based on direct counts of labeled cells. Correction factors for potential double counts were not employed because they necessitate the observation of nuclei or nucleoli that were frequently obscured by the TMB reaction product. Given the relative thickness of the sections $(50 \mu \mathrm{m})$ and the size of the raphe neurons, double counts probably did not significantly influence our estimates.

\section{Fluorescent tracing and immunohistochemistry}

An estimate of the proportion of raphe MOB neurons that contained serotonin was made by a double-label technique combining a retrograde fluorescent tracer (True blue) and 5-HT immunocytochemistry. One olfactory bulb was surgically exposed, and multiple injections of True blue (Sigma) totaling $150 \mathrm{nl}$ to $1 \mu \mathrm{l}$ were made into the bulb using a glass micropipette attached to a positive pressure hydraulic system (Shipley, 1982a) or a $1 \mu \mathrm{l}$ syringe.

Following survival times of 17 to $31 \mathrm{~d}$, the rats were deeply anesthetized and pertused transcardially with $100-200 \mathrm{ml}$ aqueous $0.9 \% \mathrm{NaCl}$, followed by $500 \mathrm{ml}$ of $0.1 \mathrm{M}$ phosphate-buffered $4 \%$ paraformaldehyde$0.05 \%$ glutaraldehyde at room temperature. The brains were left in cold fixative for 1 to $3 \mathrm{hr}$ and then placed in $20 \%$ sucrose-phosphate buffer overnight at $4^{\circ} \mathrm{C}$.

Frozen sections $30 \mu \mathrm{m}$ thick, taken from the olfactory bulb to the mid pons, were cut in the transverse plane and placed in cold PBS. Sections were (1) incubated in 2\% normal goat serum in PBS and 0.1$0.25 \%$ Triton X-100 for $1-4 \mathrm{hr}$; (2) rinsed in PBS for 15 min twice; (3) incubated in primary antibody diluted 1:100-1:1000 or left in PBS (control). The primary antibody, 5-HT conjugated to BSA, was obtained from Immunonuclear Corp. Absorption controls were performed by incubating some olfactory bulb sections in a solution containing the antibody and an excess of the antigen 5-HT-BSA; (4) incubated overnight on an agitator at $4^{\circ} \mathrm{C}$, then rinsed twice in PBS for $15 \mathrm{~min}$; (5) incubated in goat anti-rabbit IgG (1:50), goat biotinylated anti-rabbit IGG, or goat anti-rabbit IgG conjugated to fluorescein (or rhodamine) at 1:20-1:50 in PBS and 0.0-0.25\% Triton X-100 (6) rinsed in $0.05 \mathrm{M}$ phosphate buffer, mounted on gelatin-subbed slices, and coverslipped in glycerol/buffer mixture or processed further as described below.

\section{Immunocytochemistry of 5-HT fibers in $M O B$}

To visualize 5-HT-immunoreactive fibers in MOB and to compare their patterns of arborization with the results of anterograde WGA-HRP labeling of raphe projection to MOB, several bulbs were processed by the peroxidase-antiperoxidase PAP (Sternberger, 1974) or avidin-biotin-peroxidase ABC (Hsu et al., 1981) method of antibody localization. In the course of this study, it became clear that the amount of serotoninimmunoreactive axon staining was not consistent between experiments. The variation in staining intensity may be attributable to differences between animals or to technical considerations. After considerable manipulation of the experimental procedures, the best immunoreactive staining was obtained by following a rigid perfusion protocol. The rats were deeply anesthetized and perfused on ice with cold saline $\left(10^{\circ} \mathrm{C}\right)$ for $2 \mathrm{~min}$, which was followed by perfusion with $4 \%$ paraformaldehyde in phosphate buffer $\left(4^{\circ} \mathrm{C}\right)$ for $30 \mathrm{~min}$. The brains were postfixed for $1-2$ $\mathrm{hr}$ in fixative and left overnight in $20 \%$ sucrose in phosphate buffer. Sections stained for PAP immunohistochemistry were processed as described in steps (1)-(4), above, then incubated in rabbit PAP conjugates (1:100) (Dakopatts, Inc.). In most experiments, double-bridge techniques were employed (Ordronneau et al., 1981). After a $1 \mathrm{hr}$ incubation and two $10 \mathrm{~min}$ rinses in PBS, the sections were reacted for $10-20 \mathrm{~min}$ with $0.05 \%$ diaminobenzidine dihydrochloride (Sigma) and $0.01 \%$ $\mathrm{H}_{2} \mathrm{O}_{2}$ in $0.1 \mathrm{M}$ phosphate buffer.

In a few cases an attempt was made to build up serotonin in raphe axons by pretreating the rats with monoamine oxidase inhibitors. The rats were injected intraperitoneally with nialamide or pargyline (200 $\mathrm{mg} / \mathrm{kg}$ ) $2 \mathrm{hr}$ prior to perfusion.

\section{Lesion studies}

To determine whether the median and dorsal raphe nuclei are the sole sources of serotonergic fibers to MOB, electrolytic lesions were made in those nuclei. An insulated electrode was placed stereotaxically into the dorsal and median raphe nuclei of anesthetized rats. A current of 2 $\mathrm{mA}$ was passed for $20 \mathrm{sec}$. Following survival for 10-14 d the animals were killed and the brain processed for immunohistochemical localization of 5-HT, as described above.

\section{Image analysis}

Serotonin-immunoreactive axon fibers were enhanced (Fig. 1) and reconstructed using a video-based image-analysis computer system (Magiscan $2 \mathrm{~A}$; Joyce-Loebl) interfaced with a Leitz Orthoplan microscope equipped with a 3 -axis motorized stage that was controlled by the image analyzer. Enhanced images of the axons were traced throughout the plane of section at high magnification and then rescaled and placed by the computer in their proper position in a low-magnification drawing of the section. By making several high-magnification tracings of fibers throughout each selected MOB section, the distribution of serotonin- 

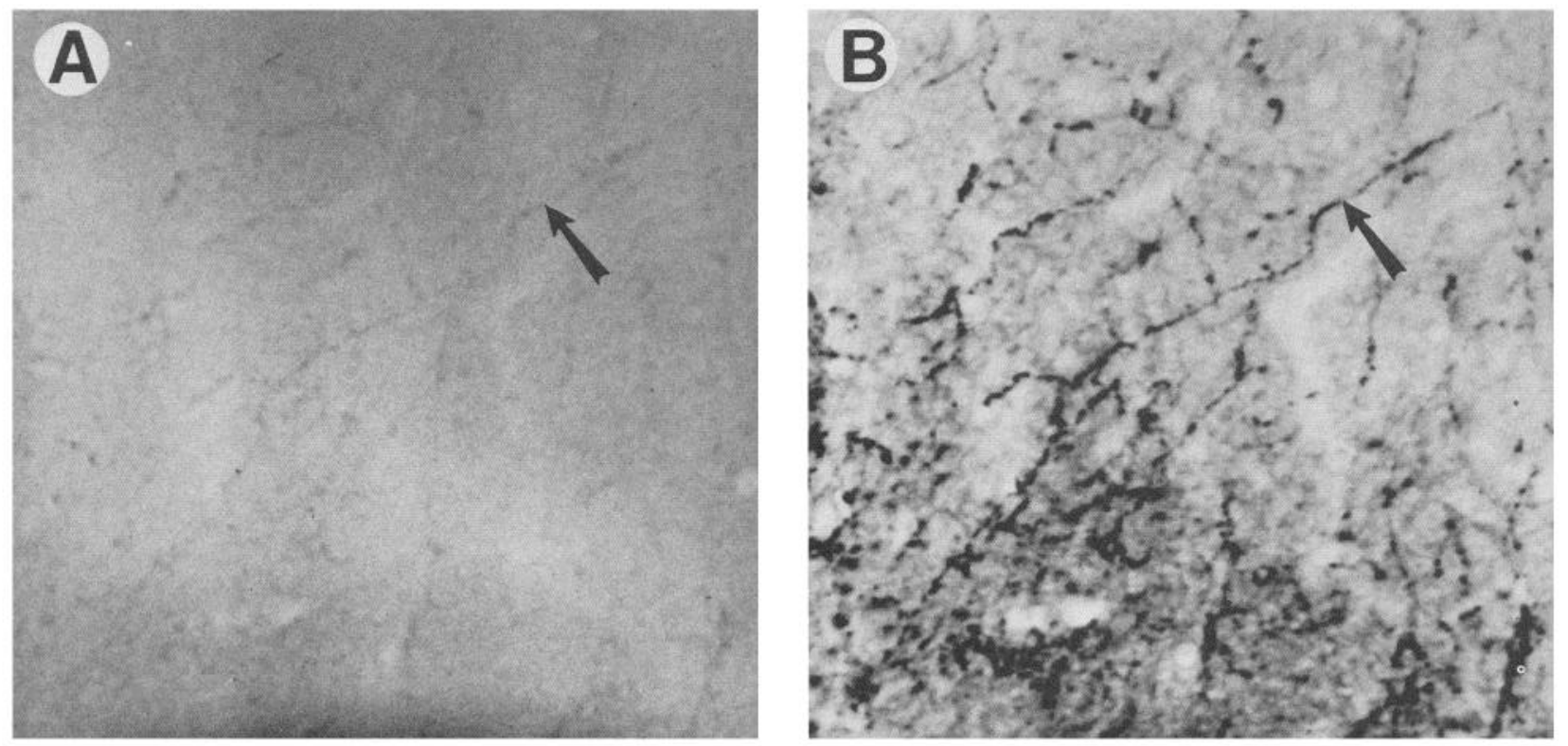

Figure 1. Bright-field video images of immunoreactive fibers in MOB viewed with an image analyzer and digital video processor. $A$, Unenhanced immunoreactive fibers. $B$, Computer-enhanced fibers displaying the ability of the computer-enhancement system to detect fibers that would otherwise be difficult to detect or not be viewed at all under normal optical conditions. Both fields are "live" images; thus the enhancements may be applied uniformly while changing the focal plane to follow fibers throughout the section thickness.

immunoreactive fibers was mapped precisely, then printed using a high-resolution laser printer (LaserJet Plus; Hewlett-Packard). Simultaneously, the Magiscan calculated the lengths and density of fibers in anatomically defined layers of the olfactory bulb. The reconstruction and fiber-quantitation software were developed in this laboratory. The density of 5-HT-immunoreactive fibers was estimated for each lamina of MOB. The estimate was obtained by selecting similar levels of the same laminar region for analysis. By using this approach, all fibers in the selected region of $30 \mu \mathrm{m}$ sections were measured using computer enhancement of the fibers and a fiber-measurement program.

Image-processing and analysis software was also developed and used to enhance and chart fluorescently labeled neurons in the raphe nuclei. For this application, the fluorescent images were detected with siliconintensified target camera (SITCAM; DAGE-MTI) and fed directly into a special purpose digital video processor (Image $\Sigma$ Model 794; Hughes Aircraft Co.). This system was especially useful for rapidly averaging, digitizing, enhancing, and storing images of faintly labeled neurons before the label faded under prolonged fluorescence illumination. The processed images were fed to the input of the Magiscan, for which software programs were developed and used to detect neurons containing both True blue retrogradely transported from MOB and 5-HT immunoreactivity. The procedure involved creating a digital binary "outline" around each True blue-labeled cell, then changing to the fluorescence filters optimal for fluorescein isothiocynate (FITC) or rhodamine and observing which of the True blue "outlines" also contained 5-HT-positive fluorescence.

\section{Results}

\section{Retrograde labeling in raphe nuclei}

After WGA-HRP was injected into MOB, retrogradely labeled neurons were observed at most rostrocaudal levels of the dorsal and median raphe nuclei (Figs. 2-4). Most labeled neurons were ipsilateral to the injection site, although some were contralateral to the injected bulb (Figs. 3, 4). Generally, the number of raphe neurons labeled was proportional to the size of the injection in the bulb. However, in the course of the anterograde tracing and immunocytochemical studies (described below), it became clear that the 5-HT raphe termination was especially heavy in the glomerular layer of the bulb. Therefore, a second series of ret- rograde tracing experiments was conducted, in which the WGAHRP injections were aimed more specifically at the glomerular layer on the medial and lateral sides of the bulb. These experiments resulted in the highest counts of retrogradely labeled neurons-ca. 600 neurons in dorsal raphe and 150 neurons in median raphe. All injections were confined to MOB, as determined by visual inspection of the injection site and the lack of retrograde label in structures such as the contralateral pyriform cortex that would have indicated excroachment of the injection upon the anterior olfactory nucleus. In a few cases where the injection site encroached slightly upon the anterior olfactory nucleus, and the glomerular layer in the bulb was particularly well saturated with the conjugate, the number of retrogradely labeled cells exceeded 1000 in the dorsal raphe and 300 in the median raphe.

Steinbusch and Nieuwenhuys (1983) have defined 4 subdivisions of the dorsal raphe nucleus: pars caudalis, dorsomedian, ventromedian, and lateral groups. WGA-HRP-labeled neurons were observed in all 4 subdivisions in all cases of injection in MOB. The majority of the raphe-MOB projection neurons were located in the ventromedial subdivision, just dorsal to and between the medial longitudinal fasciculi. Many retrogradely labeled neurons were also located in the dorsomedian subdivision, close to the cerebral aqueduct and in the lateral subdivision of the dorsal raphe nucleus. A small cluster of neurons was consistently labeled in the pars caudalis subdivision of the dorsal raphe nucleus (Fig. 4). Labeled neurons were present at all rostrocaudal levels of the median raphe nucleus. Most labeled median raphe neurons were located slightly caudal to the most concentrated group of labeled neurons in the dorsal raphe. The neurons in the dorsal and median raphe averaged $23 \times 12 \mu \mathrm{m}$ in the long and short axis, although in both the median raphe and all subdivisions of the dorsal raphe there was considerable variation of neuronal shapes and sizes. Labeled neurons ranged from 10 to $40 \mu \mathrm{m}$ in the long axis. 

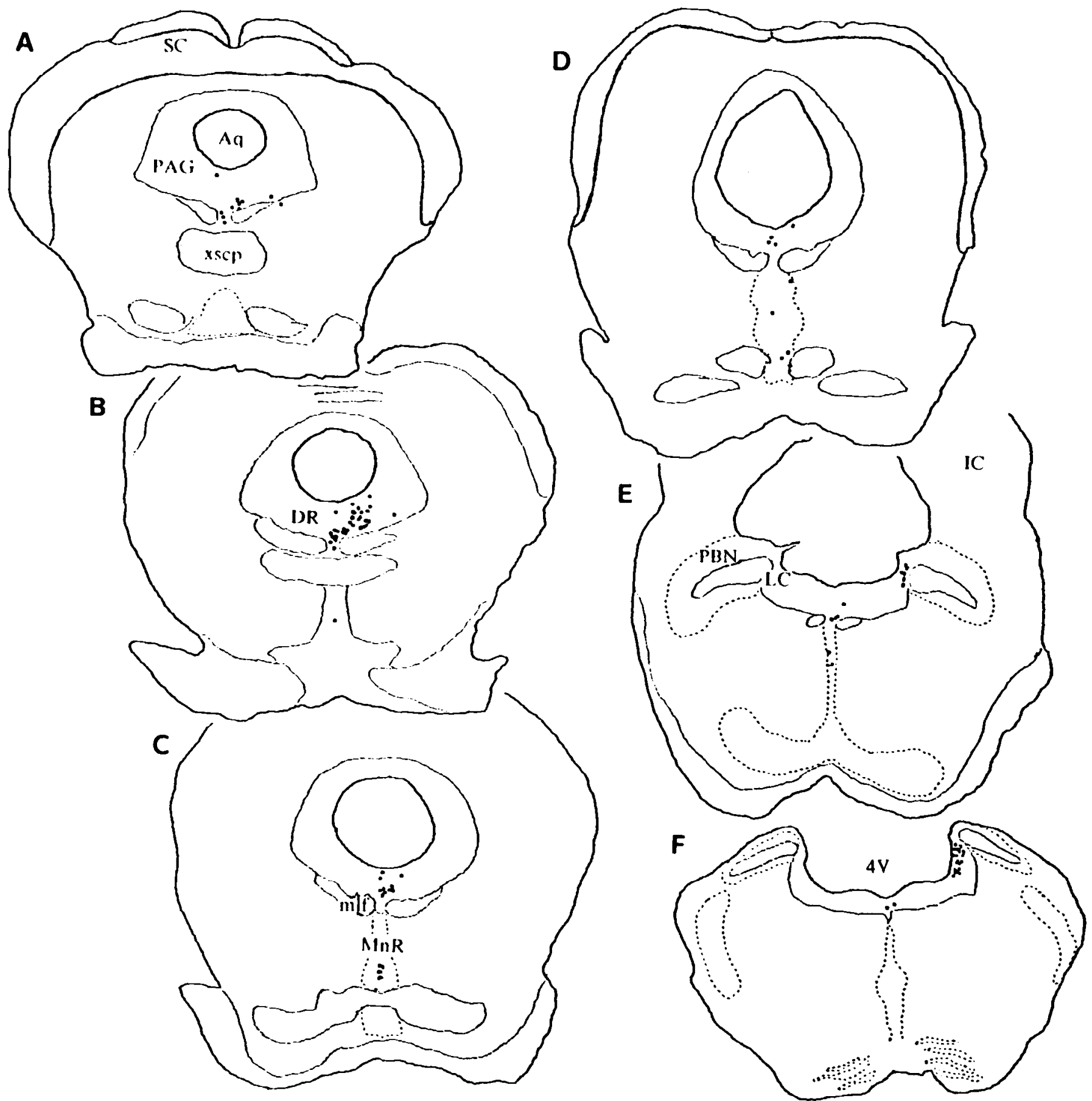

Figure 2. Distribution of retrogradely labeled neurons in the raphe nuclei following injections of WGA-HRP into the main olfactory bulb (MOB). Drawings are of representative transverse sections throughout rostral to caudal levels of the dorsal $(D R)$ and median $(M n R)$ raphe. $A q$, cerebral aqueduct; $I C$, inferior colliculus; $L C$, locus coeruleus; $m l f$, medial longitudinal fasciculus; $P A G$, periaqueductal grey; $P B N$, parabrachial nuclei; $S C$, superior colliculus; $x s c p$, decussation of superior cerebellar peduncle; $4 \mathrm{~V}$, fourth ventricle.

\section{Double-labeling experiments: fluorescent tracing and immunohistochemistry}

Following injection of True blue into the MOB, labeled neurons were observed throughout the dorsal and median raphe in the same patterns as those described for the WGA-HRP material. To determine what proportion of the raphe-MOB projection neurons are serotonergic, retrograde fluorescent labeling was combincd with indirect immunofluorescent staining using 5-HT antibodies. The vast majority of retrogradely labeled neurons were also reactive to the 5-HT antibodies (Fig. 5). Doublelabeled neurons were found in all subdivisions of the dorsal raphe and were also present in the median raphe nucleus.

\section{Anterograde tracing studies: distribution of raphe fibers in $M O B$}

To determine the location and termination patterns of raphe axons projecting to MOB, WGA-HRP was injected into the raphe nuclei and the resulting anterograde transported labeling 

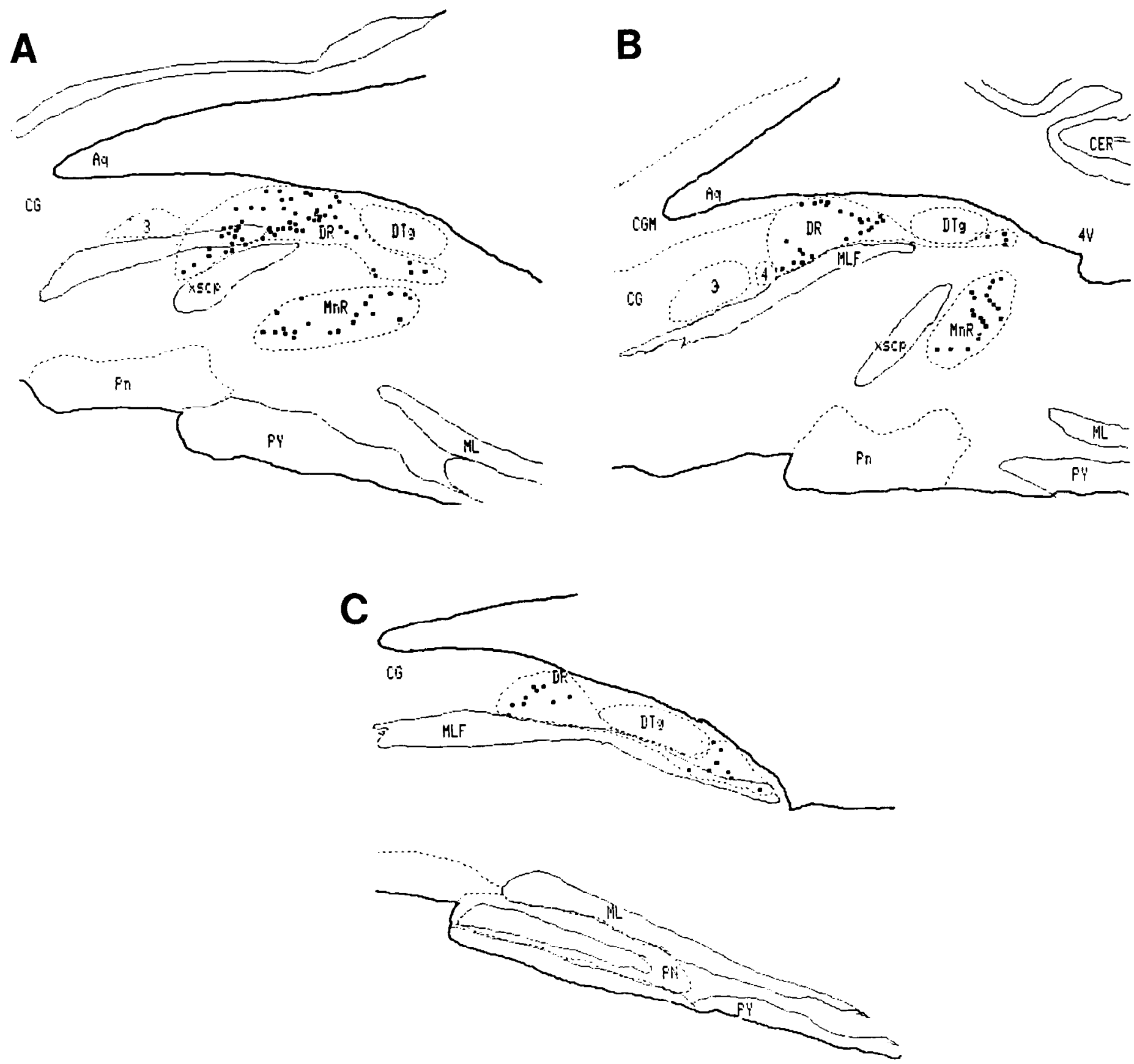

Figure 3. Drawings of sagittal $(A)$ and parasagittal $(B, C)$ sections showing the distribution of retrogradely labeled neurons in $D R$ and $M n R$ following injections of WGA-HRP into MOB. $A q$, cerebral aqueduct; $C E R$, cerebellum; $C G$, central grey; $D R$, dorsal raphe nucleus; $D T g$, dorsal tegmental nucleus; $M L$, medial lemniscus; $M L F$, medial longitudinal fasciculus; $M n R$, median raphe nucleus; $P N$, pontine nuclei; $P Y$, pyramidal tract; $x s c p$, decussation of superior cerebellar peduncle; 3 , oculomotor nucleus; 4 , trochlear nucleus.

to the MOB was analyzed. Injections wcre made in the dorsal and/or median raphe nuclei at approximately the same rostrocaudal levels that contained neurons retrogradely labeled by MOB injection. Most injections encompassed both dorsal and median raphe. However, neurons projecting to the MOB are diffusely distributed along an appreciable rostrocaudal extent of both the dorsal and median raphe nuclei; thus, it is doubtful that the injections in any one case involved all of MOB projecting neurons of the raphe nuclei. The anterograde labeling in MOB probably reflects the contribution of the dorsal more than of the median raphe neurons, however, as the injection sites were generally denser in the dorsal raphe than in the median raphe. The trajectories of many raphe-to-MOB fibers were along the ventromedial border of the rostral forebrain, continuing along the ventromedial surface of the anterior olfactory nucleus (Fig. 6C), and then entering the bulb from its exterior surface, joining fibers of the olfactory nerve. Labeled raphe fibers in the olfactory nerve layer were especially dense on the medial aspect of the olfactory bulb (Fig. 6). The fibers terminated densely in the glomeruli, which are immediately subjacent to the nerve layer. All glomeruli were labeled, although occasionally some were more heavily labeled than others (Fig. 6, $A, B$ ). Label was also present, although to a lesser degree, in the infraglomerular layers. These weakly labeled fibers appeared to enter the $M O B$ 

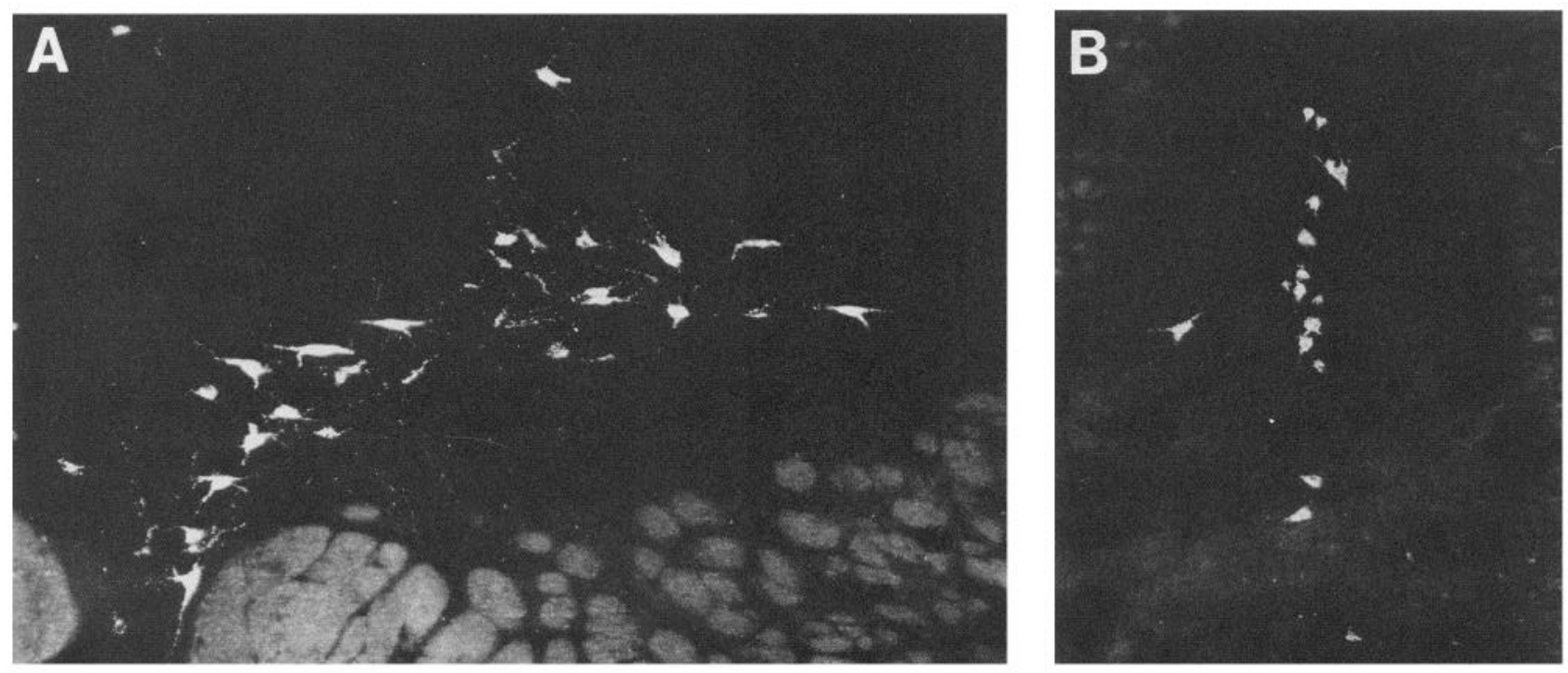

Figure 4. Dark-field photomicrographs showing retrogradely labeled neurons in dorsal $(A)$ and median $(B)$ raphe following injections of WGAHRP into MOB.

via layer 1 of the anterior olfactory cortex $(\mathrm{AON})$ and possibly via deeper layers of AON. Both olfactory bulbs contained appreciable anterograde label, owing in part to the difficulty of confining the injection to one side of these midline nuclei, although it should be recalled that the retrograde labeling experiment indicated that some contralateral raphe neurons project to the bulb. There was no label in the olfactory bulb when brain stem injection sites were either rostral or caudal to the dorsal and median raphe nuclei.

\section{Immunohistochemical studies: serotonin fiber distribution in $M O B$}

Immunoreactive serotonergic fibers ramified extensively in all glomeruli and, to a lesser extent, in the external plexiform layer, mitral cell layer, internal plexiform layer, granule cell layer, and ependymal zone (Figs. 7,8). In the glomeruli the fibers produced a dense network that did not have any obvious organization. Rather, they appeared to be randomly oriented and frequently crossed each other. There was no evidence that the innervation was restricted to any subregion within the glomeruli, nor was there any apparent preferential innervation of the periglomerular walls versus the glomerular hollows. The fibers were evenly distributed in most infraglomerular layers except that in the external plexiform layer they were mostly confined to the deeper half. The 5-HT fibers in the glomeruli ranged between 0.25 and $0.60 \mu \mathrm{m}$ in thickness and were much more densely stained than infraglomerular and most neocortical fibers (Fig. 9, $A, B, D$ ). The 5-HT glomerular fibers contained varicosities approximately every $2-20 \mu \mathrm{m}$ along their length. Most of these varicosities were large-some as large as $1.5 \mu \mathrm{m}$ in diameter-while others were only slightly larger than the thickness of the axon. Serotonergic fibers in the infraglomerular layers often had a strikingly different morphology than the glomerular fibers. Although fibers in the external plexiform layer were often of the same thickness as those in the glomeruli, they contained noticeably fewer and smaller varicosities. Most infraglomerular fibers, however, were thinner $(0.25-0.35)$ than glomerular fibers and contained varicosities that were often barely larger than the thickness of the axon. The infraglomerular fibers generally stained less intensely than glomerular fibers.

In addition to the morphological and stain intensity differences of serotonergic fibers in the MOB, fiber density gradients were also observed (Figs. 7, 8). Fiber and length density analyses were made on sections from the midrostral to caudal levels on the lateral side of the MOB in 3 rats. The highest density of 5-HT-immunoreactive fibers was in the glomeruli. The average fiber density was $9 \mu \mathrm{m} / 100 \mu \mathrm{m}^{2}$ in the glomeruli, which was more than 3 times the density in the granule cell layer, external plexiform layer, and ependymal zone, and approximately twice the density of 5-HT fibers in the narrow mitral and internal plexiform layers. When the total 5-HT fiber lengths were calculated for each layer in $\mathrm{MOB}$, the glomerular fibers were even more predominant, because of the area occupied by the glomerular layer, as compared to other laminae (Fig. 8). The heavy preferential distribution of 5-HT-immunoreactive fibers and varicosities in the glomerular layers in the MOB was in sharp contrast to the widespread and relatively modest degree of laminar preferentiality observed in most parts of the neocortex in our material.

\section{Lesion experiments}

Confirmation that the median and dorsal raphe are the sole source of 5-HT in MOB was obtained by destroying these nuclei. Following large electrolytic lesions that encompassed both nuclei, but no other structures that projected to MOB, no 5-HTimmunoreactive fibers could be found in MOB (Fig. 9C).

\section{Discussion}

The present results demonstrate that there is an extensive, laminated serotonergic projection from the raphe nuclei to the olfactory bulb. The experiments show that as many as 1300 raphe neurons project to MOB; most of these neurons contain serotonin. The density of 5-HT fibers in the glomerular layer is 2 to 3 times greater than in any other layer in MOB. Serotonergic fibers in the glomerular layer were generally thicker, more intensely stained, and contained larger varicosities than most 5-HT fibers in infraglomerular layers. 

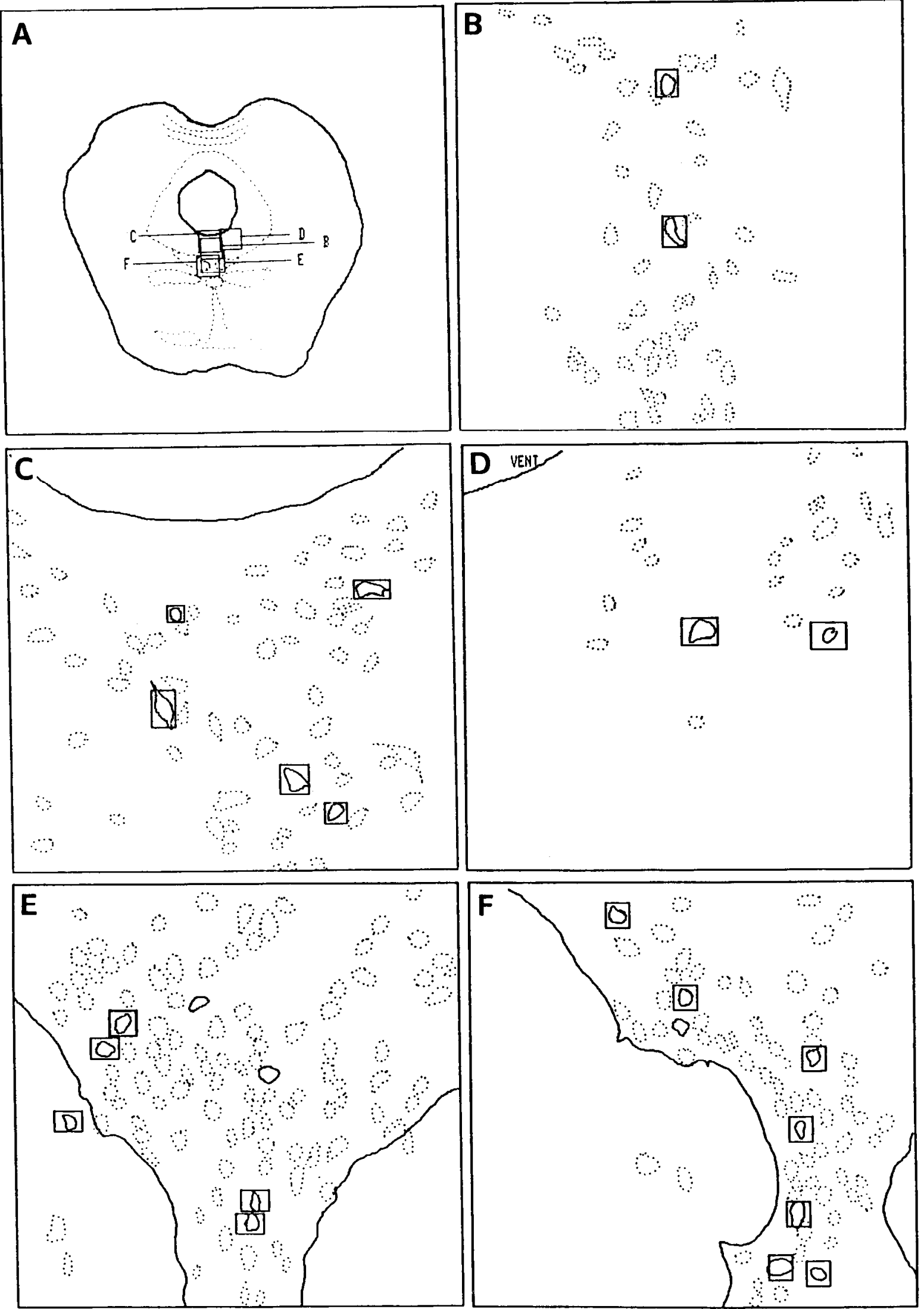

Figure 5. Drawings showing the distribution of double-labeled neurons in DR following injections of True blue into MOB, and reacting sections displaying 5-HT immunoreactivity. The serotonergic neurons are outlined with dots, True blue cells are solid lines, and double-labeled cells are shown within rectangular outlines. $A$, Representative section and general regions from which $B-F$ are taken. 

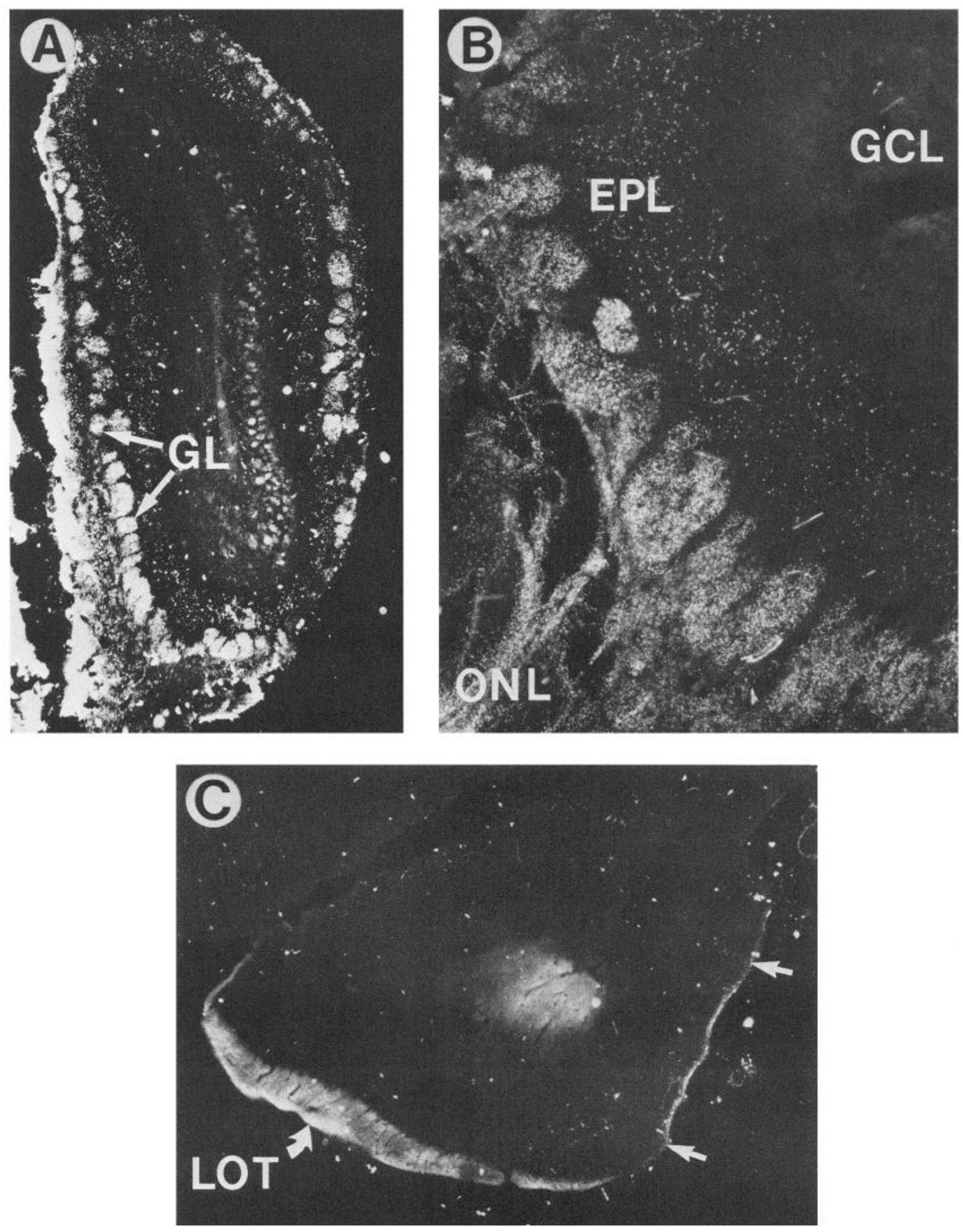

Figure 6. Dark-field photomicrographs of anterograde label in MOB $(A, B)$ and the anterior olfactory nucleus $(C)$ following injection of WGAHRP into DR and MnR. $A$, All glomeruli appear to contain HRP reaction product, although some glomeruli are more densely labeled than others. The anterograde label in infraglomerular layers is sparse and difficult to visualize. $A$ and $B$, The label appears to enter MOB from the ventromedial portion of the olfactory nerve. Fibers can be visualized better in $B$ where they seem to stream into the glomeruli via the olfactory nerve. $C$, At the level of the anterior olfactory nucleus, the WGA-HRP reaction product is located along the ventromedial border (arrow) and within the medial neuropil. $E P L$, external plexiform layer; $G C L$, granule cell layer; $G L$, glomerular layer; $L O T$, lateral olfactory tract; $O N L$, olfactory nerve layer.

\section{Magnitude of raphe input to $M O B$}

Earlier studies suggested that only a few raphe neurons projected to the MOB (Davis et al., 1978; deOlmos et al., 1978). On the basis of retrograde labeling, we estimate that anywhere from 600 to 1000 neurons in the dorsal raphe nucleus project to the $\mathrm{MOB}$ in the adult rat, depending on the size and location of the
WGA-HRP injection sites in MOB. Two factors probably explain why our estimate of the magnitude of the raphe projection to MOB is higher than that in earlier studies. The first is that we used a more sensitive retrograde tracer, WGA-HRP, than was previously available; the second factor is that we aimed our injections at the glomerular layer, where there is a particularly dense termination of raphe fibers. Injections within the terminal 


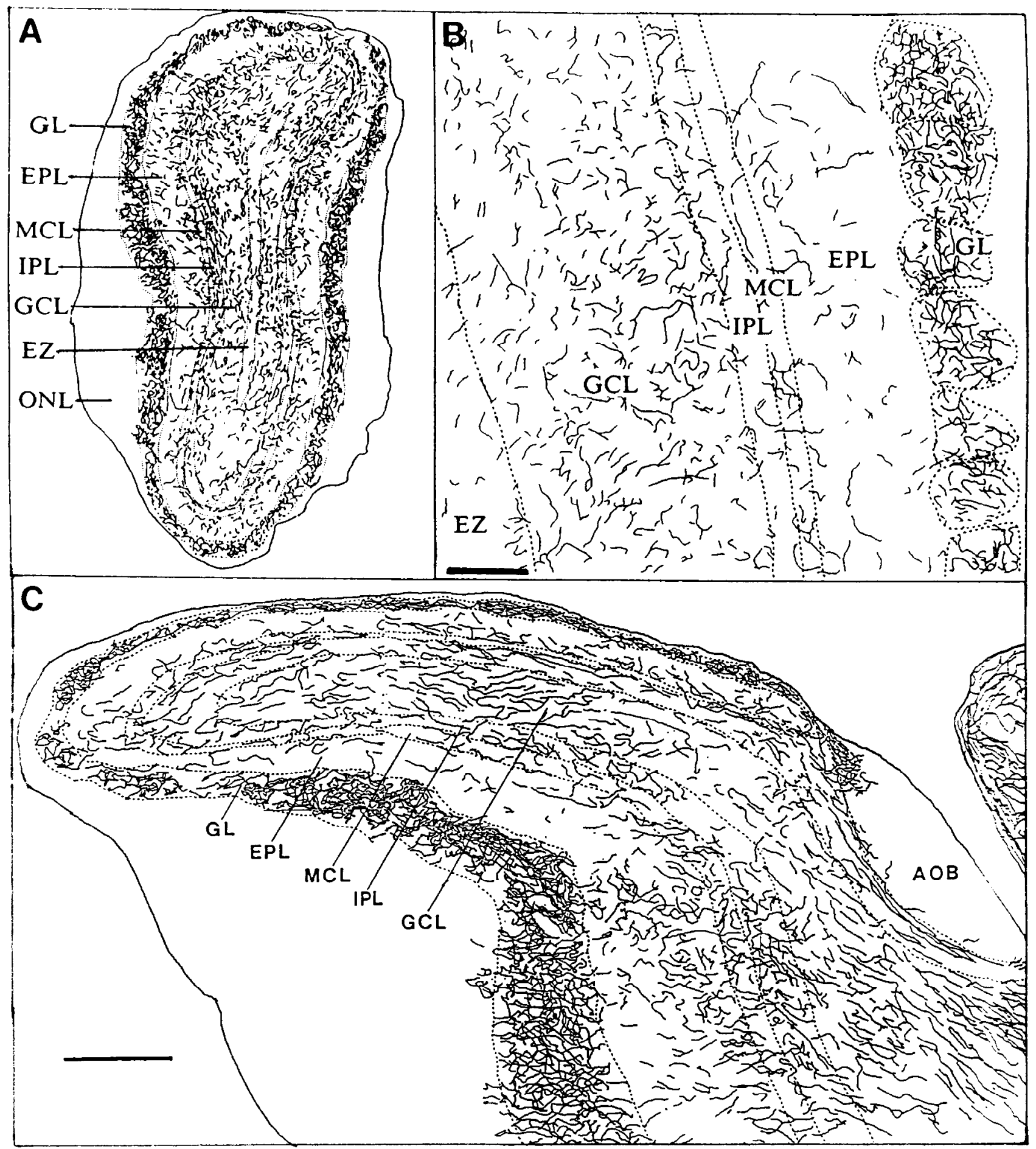

Figure 7. Computer-aided drawings of 5-HT immunoreactive fibers in the adult rat. $A$, Low magnification drawing of an entire transverse section of MOB. $B$. Higher magnification showing the density of 5-HT immunoreactive fibers in a representative region of MOB. The glomeruli receive the most fibers while the infraglomeruli portions receive considerable, yet lighter, 5-HT fibers. $C$, Low magnification drawing of a parasagittal section showing the distribution of fibers in the olfactory bulb. $A O B$, accessory olfactory bulb; $E P L$, external plexiform layer; $E Z$, ependymal zone; $G C L$, granule cell layer; $G L$, glomerular layer; $I P L$, internal plexiform layer; $M C L$, mitral cell layer; $O N L$, olfactory nerve layer. Bars $100 \mu \mathrm{m}(B)$; $500 \mu \mathrm{m}(C)$.

field of raphe neurons probably facilitate the uptake of the tracer into raphe fibers and result in more efficient retrograde labeling of their cell bodies. Although it is very difficult to define the effective size of a WGA-HRP injection site, it is clear that none of our experiments succeeded in producing dense injection cores encompassing the majority of the glomeruli in the bulb. Thus, it is possible that our highest cell counts still significantly underestimate the number of raphe neurons that project to the bulb.

The distribution of retrogradely labeled raphe neurons corresponded approximately to the distribution of labeled cells observed by Araneda et al. (1980, 1981) following injection of 
DISTRIBUTION OF 5-HT FIBERS IN THE ADULT MOB

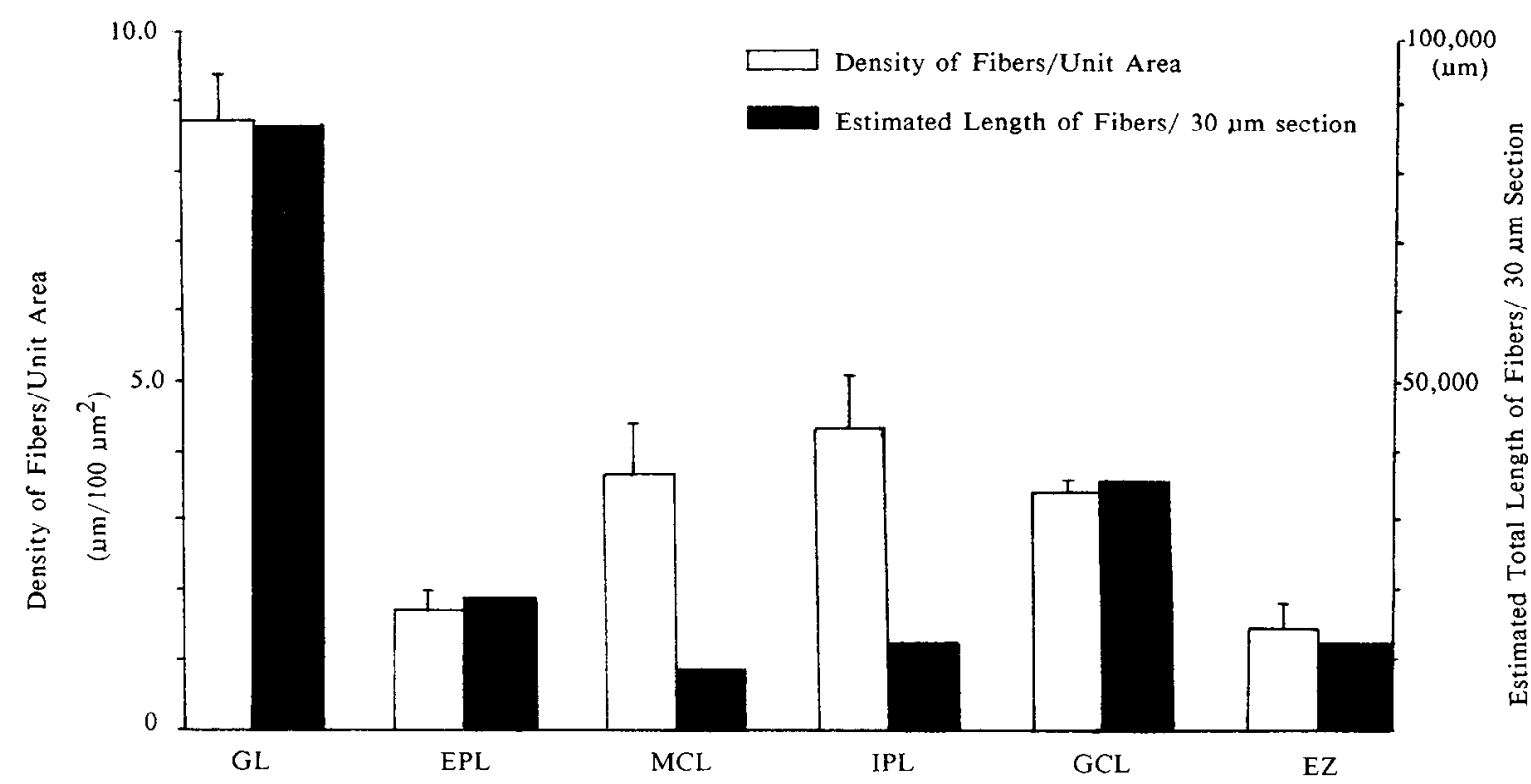

Figure 8. Graph showing the density of 5-HT immunoreactive fibers per unit area (mean and SD, $n=3-4$ rats) and the estimated total length of fibers in each section for each lamina in the rat MOB. $E P L$, external plexiform layer; $E Z$, ependymal zone; $G C L$, granule cell layer; $G L$, glomerular layer; $I P L$, internal plexiform layer; $M C L$, mitral cell layer.

${ }^{3} \mathrm{H}-5-\mathrm{HT}$ into the MOB, and by others (Broadwell and Jacobowitz, 1976; Davis et al., 1978; deOlmos et al., 1978; GuevaraAguillar et al., 1982) following unconjugated HRP injections into the MOB. Neurons in both the dorsal and median raphe nuclei projected to the MOB. The number of labeled neurons in the dorsal raphe was always substantially greater than that in the median raphe. On the other hand, the number of labeled dorsal raphe neurons was always substantially less than the total number of neurons in that nucleus. In the present investigation, we did not determine the percentage of raphe ncurons projecting to the bulb nor did we investigate whether raphe neurons that project to the MOB also preferentially project collaterals to other olfactory areas, although this is an interesting question, as our immunocytochemical material indicates that 5-HT fibers heavily innervate a number of retrobulbar olfactory structures.

\section{Neurochemical content of raphe input to $M O B$}

The combined 5-HT immunofluorescence-retrograde fluorescent tracing results indicate that most of the raphe neurons that project to the MOB contain serotonin. Only a few True bluelabeled raphe neurons did not have detectable 5-HT immunoreactivity. There are at least 3 possible explanations of the lack of 5-HT staining in these neurons: (1) The 5-HT antibodies may have failed to demonstrate all 5-HT neurons; (2) the 5-HT label may have been present but quenched by True blue, since competitive effects between 2 different fluorescent labels are known to occur (Alheid et al., 1984); and (3) some raphe-MOB projection neurons may contain a transmitter(s) other than serotonin. It has been reported that some neurons in the dorsal and median raphe contain dopamine (Hökfelt et al., 1976; Ochi and Shimizu, 1978; Nagatsu et al., 1979; Davis and Macrides, 1983), GABA/GAD (Belin et al., 1979; Nagai et al., 1985), cholecystokinin (CCK) (Vanderhaeghen et al., 1980), leu- and met-enkephalin (Hökfelt et al., 1977; Uhl et al., 1979; Glazer et al., 1981; Moss et al., 1981), substance P (Ljungdahl et al., 1978), and vasoactive intestinal polypeptide (VIP) (Loren et al., 1979; Sims et al., 1980), in addition to the predominant transmitter in the system, serotonin (for a review, see Steinbusch, 1981). It is also possible that the retrogradely labeled 5-HTpositive neurons observed in the present study contain additional neuroactive molecules, such as those mentioned above. It would be useful to search for such colocalized molecules, since their combined actions on postsynaptic targets would presumably be different than the actions of serotonin alone.

The strength of the serotonergic raphe MOB projection is quite great and markedly exceeds that described in earlier reports. The magnitude of this projection compares favorably with that of the recently reported heavy noradrenergic projection from the locus coeruleus to MOB in the rat (Shipley et al., 1985). Together, these findings indicate that in the rodent brain, the main olfactory bulb is one of the major telencephalic targets of ascending monoaminergic systems. The functional significance of this fact remains to be elucidated, but it is intriguing that these 2 monoaminergic systems so heavily innervate the firstorder olfactory-processing structure in a macrosmatic animal. Since recent theories suggest that monoaminergic systems play complementary roles in sensory signal processing (Waterhouse et al., 1980, 1986), it would be interesting to know if these same monoaminergic systems innervate the olfactory bulbs to the same degree in specics less depcndent on olfaction than rodents.

\section{Raphe serotonergic fiber patterns in $M O B$}

The anterograde fiber-labeling and immunocytochemical experiments provided new information about the axonal trajectories and termination patterns of the raphe projection to the bulb. A significant proportion of raphe axons enter the MOB via an unusual route that appears to be unique among centrifugal afferent inputs to the bulb. The anterograde WGA-HRP tracing 

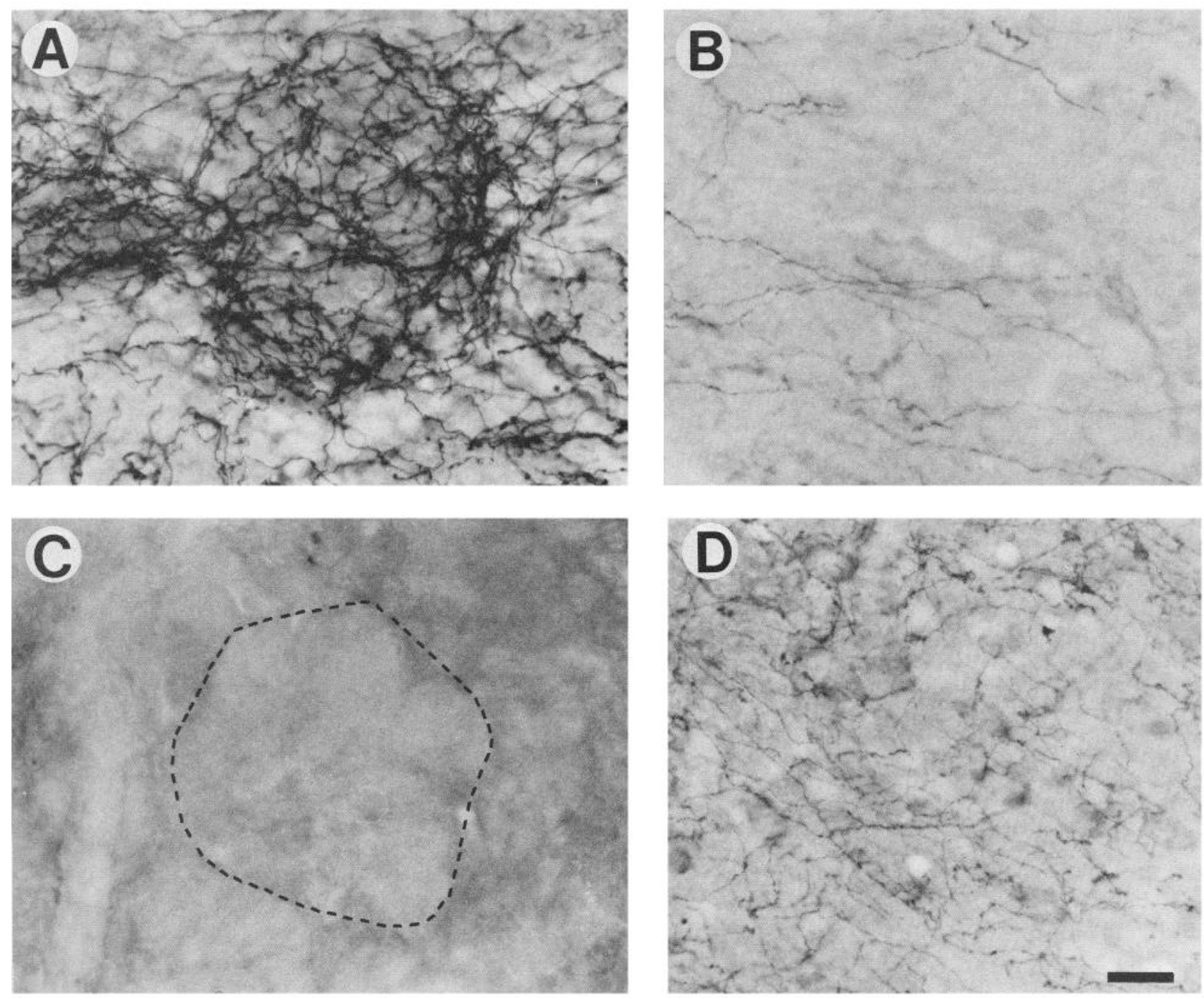

Figure 9. Bright-field photomicrographs of 5-HT immunoreactive fibers in the $(A)$ glomeruli, $(B)$ granule cell layer, and $(D)$ cerebral cortex. $C$, Following lesion of the DR and MnR, 5-HT immunoreactivity is nearly totally abolished, indicating that DR and MnR are the sole sources of serotonergic afferent fibers to MOB. Bar in $D, 50 \mu \mathrm{m} ; A-D$ same magnification.

showed very heavy label within the ventral and medial parts of the olfactory nerve layer and fibers were observed extending from the nerve layer into the olfactory glomeruli. We did not, however, visualize appreciable numbers of immunocytochemically stained serotonergic fibers in the olfactory nerve layer, nor have other investigators (Steinbusch, 1981; Takeuchi et al., 1982). The basis for this discrepancy is unclear. We have considered the possibility that the WGA-HRP label in the nerve layer might be due to the spread of HRP from the injection region through the ventricular system and subarachnoid space to the nerve layer. We feel that this is unlikely, however, because there was no other label along the ventricles other than that found in the immediate vicinity of the injection site, nor was there nonspecific label present over any other part of the brain's surface. Moreover, there have been many cases in which WGAHRP was used to label the connections of the locus coeruleus (Aston-Jones et al., 1986). This nucleus is even closer to the ventricular system than the raphe, and our injections in locus coeruleus resulted in heavy anterograde labeling in MOB, but no labeling of the olfactory nerve layer (unpublished observations). Therefore, we consider it unlikely that the olfactory nerve labeling seen in the raphe injection cases is due to ventricular spread. Another possible explanation for the anterograde label in the nerve is that it belongs to fibers originating in the raphe that do not contain serotonin. Recently, substance P-immunoreactive fibers have been identified in the olfactory nerve layer in rats (Baker, 1986) and it is possible that these fibers originate from raphe soma. In addition to this curious axonal route of entry into the MOB through the olfactory nerve layer, other raphe axons appear to enter via the substance of the anterior olfactory nucleus. Thus, it is possible that raphe axons enter the MOB by at least 2 different pathways: the olfactory nerve layer and the rostral limb of the anterior commissure. Further insight into the meaning of the 2 potential routes into the MOB may be obtained from ultrastructural studies aimed at determining the postsynaptic targets of the 5-HT synapses in glomerular and infraglomerular laminae. The divergent routes may be due to differences in the origins of the raphe fibers and their termination patterns in the MOB. The WGA-HRP injections in the dorsal and median raphe nuclei generally resulted in heavy glomerular terminal label; infraglomerular terminal label in the MOB was always weaker than what might have been expected from the immunocytochemical staining. Most of the injections failed to encompass all of the median raphe, however; thus, it is possible 
that median raphe neurons project preferentially to the infraglomerular layer. Immunocytochemical staining of 5-HT fibers in the MOB indicated morphological differences between glomerular and infraglomerular fibers. Serotonergic fibers in the glomeruli were thicker, contained more numerous and larger varicosities, and were more intensely stained than most infraglomerular fibers. Whether these morphological, staining, and positional differences of terminal patterns in the MOB are associated with differential projections from the dorsal and median raphe nuclei is unknown. Further study of the specific contributions of the dorsal and median raphe to MOB is needed to clarify these issues.

The preferential localization of 5-HT fibers in the glomeruli in MOB is striking. The density of the fibers in glomeruli is 23 times that in any other layer in the MOB. In addition, the thicker fibers and larger varicosities of serotonergic axons in the glomeruli, compared to infraglomerular axons, suggest that even more than 2-4 times the amount of serotonin may be present and available for release in glomerular, as compared to infraglomerular, layers. Other cortical structures have differential laminar innervation by 5-HT fibers, but none seem to be as striking as the olfactory bulb (Lidov et al., 1980; Steinbusch, 1981; Kosofsky et al., 1984). Thus, the glomeruli of the main olfactory bulb may be a major site of serotonergic influence.

What might be the targets of the heavy serotonergic innervation to MOB? The preferential distribution of serotonergic fibers in specific layers of MOB may ultimately help to answer this question. The glomeruli are the first relay and processing sites of olfactory information reaching the brain. Primary olfactory receptor neurons (PONs) located in the nasal epithelium project from the epithelium to the bulb, where they ramify and terminate profusely and exclusively in the glomeruli. The postsynaptic targets of PON synapses include the dendrites of the second-order relay neurons, mitral and tufted cells, and possibly also local interneurons, collectively called peri- or juxtaglomerular neurons (Pinching and Powell, 1971a, b). Both the anterograde tracing and 5-HT-immunostaining results of the present study indicate that raphe 5-HT fibers terminate especially heavily in the glomeruli and less densely in infraglomerular layers. Thus, it is likely that the major targets of raphe 5-HT synapses are either the dendrites of mitral, tufted, or periglomerular cells or possibly the PON terminals themselves. Serotonergic fibers innervate infraglomerular layers less densely than the glomerular layer. The major targets of 5-HT fibers in infraglomerular layers may be the dendrites or cell bodies of granule cells, since these neuronal elements predominate in infraglomerular layers. A previous electron-microscopic study using uptake of isotopically labeled 5-HT also suggested this possibility (Halasz et al., 1978). However, ultrastructural studies using immunocytochemistry techniques are needed to resolve this issue, since 5-HT uptake/binding may occur at either pre- or postsynaptic sites.

In any event, it seems reasonable to conclude that because of their glomerular location, many raphe serotonergic terminals are presynaptic to neural elements participating in the first level of olfactory synaptic integration in the brain. As such, the raphe 5-HT system would be expected to have a major impact upon olfactory information processing, since actions exerted at the initial level of synaptic integration would be reflected in all subsequent levels of synaptic transfer in the olfactory system. Since serotonergic axons are also present in other layers of MOB, albeit at lower density and with different morphology, they may also act on infraglomerular structures such as granule cells.

\section{Physiological roles of 5-HT}

Little is known of the neurophysiological actions of serotonin on the activity of olfactory bulb neurons. Inhibitory effects have been reported (Baumgarten et al., 1963; Bloom et al., 1964), but previous studies were conducted without the knowledge that 5-HT terminals terminate heavily in glomerular structures. Neurophysiological studies of the effects of raphe stimulation and 5-HT application at the glomerular level are clearly needed and are currently in progress in this laboratory.

An intriguing hypothesis concerning the potential functional significance of raphe 5-HT projections to the glomeruil is that these synapses may play a role in sensitization or dishabituation. In an elegant series of experiments, Kandel and co-workers (Klein and Kandel, 1978, 1980; Castellucci et al., 1980) demonstrated that serotonin mediates the neural sensitization produced by arousing stimuli of a previously habituated simple behavior, the gill withdrawal reflex in Aplysia. Mammalian olfactory neurons are notoriously prone to habituate to steadily maintained odor stimuli. The strategic anatomical location of many raphe 5-HT synapses at the first level of synaptic transfer in the olfactory system is similar to the location of sensitizing serotonergic synapses on the terminals of primary sensory neurons in Aplysia. Thus, a potential role for 5-HT synapses in olfactory bulb glomeruli might be to mediate dishabituation to behaviorally salient olfactory stimuli. Such a role is amenable to direct experimental study in the rat olfactory bulb and would constitute a useful test of the generalization that 5-HT synapses, which have widespread deployment in the vertebrate CNS, are involved in sensitization-like operations in many neural systems.

Other recent experiments have shown that 5-HT release in rat somatosensory cortex depresses sensory-evoked neuronal discharges relative to background firing, which might, in effect, decrease the sensory signal-to-noise ratio. Serotonin also seems to depress the actions of other neurotransmitters on neocortical neurons (Waterhouse et al., 1986). Whether raphe 5-HT inputs have similar actions on olfactory bulb neurons remains to be determined. These and other hypotheses regarding 5-HT synaptic function, however, should find a fertile testing ground in the orderly 5 -HT projection to a well-characterized cortical architectonic unit, the olfactory bulb glomerulus.

\section{References}

Alheid, G. F., J. Carlsen, J. deOlmos, and L. Heimer (1984) Quantitative determination of collateral anterior olfactory nucleus projections using a fluorescent tracer with an algebraic solution to the problem of double retrograde labeling. Brain Res. 192: 17-22.

Araneda, S., H. Gambrani, C. Font, A. Calas, J.-F. Pujol, and P. Bobillier (1980) Retrograde axonal transport following injection of $\left[{ }^{3} \mathrm{H}\right]-$ serotonin into the olfactory bulb. II. Radioautographic study. Brain Res. 196: 417-427.

Araneda, S., C. Font, J.-F. Pujol, and P. Bobillier (1981) Is the retrograde axonal transport of ${ }^{3} \mathrm{H}-5-\mathrm{HT}$ a specific process of serotonergic neurons? J. Physiol. (Paris) 77: 233-235.

Aston-Jones, G., M. Ennis, V. A. Pieribone, W. T. Nickell, and M. T. Shipley (1986) The brain nucleus locus coeruleus: Restricted afferent control of a broad efferent network. Science 234: 734-737.

Baker, H. (1986) Species differences in the distribution of substance $P$ and tyrosine hydroxylase immunoreactivity in the olfactory bulb. J. Comp. Neurol. 252: 206-226.

Baumgarten, R., F. E. Bloom, A. P. Oliver, and G. C. Salmoiraghi (1963) Response of individual olfactory nerve cells to microelectrophoretically administered chemical substances. Pfluegers Arch. Physiol. 277: 125-140. 
Belin, M. R., M. Tappz, A. McRae-Degueurce, P. Bobillier, and J. F. Pujol (1979) GABA-accumulating neurons in the nucleus raphe dorsalis and periaqueductal gray in the rat: A biochemical and radioautographic study. Brain Res. 170: 279-297.

Bloom, F. E., E. Costa, and G. C. Salmoiraghi (1964) Analysis of individual rabbit olfactory bulb neuron responses to the microelectrophoresis of acetylcholine, norepinephrine and serotonin synergists and antagonists. J. Pharmacol. Exp. Ther. 146: 16-23.

Broadwell, R. D., and D. M. Jacobowitz (1976) Olfactory relationships of the telencephalon and diencephalon in the rabbit. III. The ipsilateral centrifugal fibers to the olfactory bulbar and retrobulbar formations. J. Comp. Neurol. 170: 321-346.

Carson, K. A. (1984) Quantitative localization of neurons projecting to the mouse main olfactory bulb. Brain Res. Bull. 12: 629-634.

Castellucci, V. F., F. R. Kandel, J. H. Schwartz, F. D. Wilson, A. C. Nairn, and P. Greengard (1980) Intracellular injection of the catalytic subunit of cyclic AMP-dependent protein kinase simulates facilitation of transmitter release underlying behavioral sensitization in Aplysia. Proc. Natl. Acad. Sci. USA 77: 7492-7496.

Davis, B. J., and F. Macrides (1983) Tyrosine hydroxylase immunoreactive neurons and fibers in the olfactory system of the hamster. J. Comp. Neurol. 214: 427-440.

Davis, B. J., F. Macrides, W. M. Youngs, S. P. Schneider, and D. L. Rosene (1978) Efferents and centrifugal afferents of the main and accessory olfactory bulbs in the hamster. Brain Res. Bull. 3: 59-72.

deOlmos, J., H. Hardy, and L. Heimer (1978) The afferent connections of the main and accessory olfactory bulb formations in the rat: An experimental HRP study. J. Comp. Neurol. 181: 213-244.

Glazer, E. J., H. W. M. Steinbusch, A. A. J. Verhofstad, and A. J. Basbaum (1981) Serotonin neurons in nucleus raphe dorsalis and paragigantocellularis of the cat contain enkephalin. J. Physiol. (Paris) 77: 241-245.

Guevara-Aguilar, R., L. P. Solano-Flores, O. A. Donatti-Albrarran, and H. U. Aguilar-Baturoni (1982) Differential projections from locus coeruleus to olfactory bulb and olfactory tubercle: An HRP study. Brain Res. Bull. 8: 711-719.

Halasz, N., A. Ljungdahl, and T. Hökfelt (1978) Transmitter histochemistry of the rat olfactory bulb. II. Hluorescence histochemical, autoradiographic and electron microscopic localization of monoamines. Brain Res. 154: 253-271.

Hökfelt, T., O. Johansson, K. Fuxe, M. Goldstein, and D. Park (1976) Immunohistochemical studies on the localization and distribution of monoamine neuron systems in the rat brain. I. Tyrosine hydroxylase in the mesencephalon and diencephalon. Med. Biol. 54: 427-453.

Hökfelt, T., R. Elde, O. Johansson, L. Terenisu, and L. Stein (1977) The distribution of enkephalin-immunoreactive cell bodies in the rat central nervous system. Neurosci. Lett. 5: 25-31.

Hsu, S. M., L. Raine, and H. Fanger (1981) The use of avidin-biotinperoxidase complex (ABC) in immunoperoxidase techniques: A comparison between unlabeled antibody (PAP) procedures. J. Histochem. Cytochem. 24: 577-580.

Klein, M., and E. R. Kandel (1978) Presynaptic modulation of voltagedependent $\mathrm{Ca}^{2+}$ current: Mechanism for behavioral sensitization in Aplysia californica. Proc. Natl. Acad. Sci. USA 75: 3512-3516.

Klein, M., and E. R. Kandel (1980) Mechanism of calcium current modulation underlying presynaptic facilitation and behavioral sensitization in Aplysia. Proc. Natl. Acad. Sci. USA 77: 6912-6916.

Kosofsky, B. E., M. E. Molliver, J. H. Morrison, and S. L. Foote (1984) The serotonin and norepinephrine innervation of primary visual cortex in cynomolgus monkey (Macaca fascicularis). J. Comp. Neurol. 230: $168-178$.

Lidov, H. G. W., R. Grzanna, and M. E. Molliver (1980) The serotonin innervation of the cerebral cortex in the rat: An immunocytochemical analysis. Neuroscience 5: 207-227.

Ljungdahl, A., T. Hökfelt, and G. Nilsson (1978) Distribution of substance P-like immunoreactivity in the central nervous system in the rat. I. Cell bodies and terminals. Neuroscience 3: 861-943.

Loren, I., P. C. Emson, J. Fahrenkrug, A. Björklund, J. Alumets, R. Hakanson, and F. Sundler (1979) Distribution of vasoactive polypeptide in rat and mouse brain. Neuroscience 4: 1953-1976.

Mesulam, M.-M. (1978) Tetramethylbenzidine for horseradish per- oxidase neurohistochemistry: A non-carcinogenic blue reaction product with superior sensitivity for visualizing neural afferents and efferents. Histochem. Cytochem. 26: 106-117.

Moss, M. S., E. J. Glazer, and A. L. Basbaum (1981) Enkephalinimmunoreactive perikarya in the cat raphe dorsalis. Neurosci. Lett. 21: 33-37.

Nagai, T., T. Maeda, H. Imai, P. L. McGeer, and E. G. McGreer (1985) Distribution of GABA-T-intensive neurons in the rat hindbrain. J. Comp. Neurol. 231: 260-269.

Nagatsu, I., S. Inagaki, Y. Kondo, N. Karasawa, and T. Nagatsu (1979) Immunofluorescent studies on the location of tyrosine hydroxylase and dopa- $\beta$-hydroxylase in the mes-, di-, and telencephalon of the rat using unperfused fresh frozen sections. Acta Histochem. Cytochem. 12: 20-37.

Ochi, J., and K. Shimizu (1978) Occurrence of dopamine-containing neurons in the midbrain raphe nuclei of the rat. Neuroscience $8: 317-$ 320.

Ordronneau, P., P. B.-M. Lindstrom, and P. Petrusz (1981) Four unlabeled antibody bridge techniques: A comparison. J. Histochem. Cytochem. 29: 1397-1404.

Paxinos, G., and C. Watson (1982) The Rat Brain in Stereotaxic Coordinates, Academic, New York.

Pinching, A. J., and T. P. S. Powell (1971a) The neuron types of the glomerular layer of the olfactory bulb. J. Cell Sci. 9: 305-345.

Pinching, A. J., and T. P. S. Powell (1971b) The neuropil of the glomeruli of the olfactory bulb. J. Cell Sci. 9: 347-377.

Shepherd, G. M. (1983) In Neurobiology, pp. 211-225, Oxford U. P., New York.

Shipley, M. T. (1982a) A simple, low-cost hydraulic pressure device for making microinjections in the brain. Brain Res. Bull. 8: 237-239.

Shipley, M. T. (1982b) Insular cortex projections to the nucleus solitarius and brainstem visceromotor regions in the mouse. Brain Res. Bull. 8: 139-148.

Shipley, M. T., and G. D. Adamek (1984) The connections of the mouse olfactory bulb: A study using orthograde and retrograde transport of wheat germ agglutinin conjugated to horseradish peroxidase. Brain Res. Bull. 12: 669-688.

Shipley, M. T., F. J. Halloran, and J. de la Torre (1985) Surprisingly rich projection from locus coeruleus to the olfactory bulb in the rat. Brain Res. 329: 294-299.

Sims, K. B., D. L. Hoffman, S. I. Said, and E. A. Zimmerman (1980) Vasoactive intestinal polypeptide (VIP) in mouse and rat brain an immunocytochemical study. Brain Res. 186: 165-183.

Steinbusch, H. W. M. (1981) Distribution of serotonin-immunoreactivity in the central nervous system of the rat. Cell bodies and terminals. Neuroscience 6: 557-618.

Steinbusch, H. W. M., and R. Nieuwenhuys (1983) The raphe nuclei of the rat brainstem: A cytoarchitectonic and immunohistochemical study. In Chemical Neuroanatomy, P. C. Emson, ed., pp. 131-207, Raven, New York.

Sternberger, L. A. (1974) In Immunocytochemistry, Prentice-Hall, Englewood Cliffs, NJ.

Takeuchi, Y., H. Kimura, and Y. Sano (1982) Immunohistochemical demonstration of serotonin nerve fibers in the olfactory bulb of the rat, cat and monkey. Histochemistry 75: 461-471.

Uhl, G. R., R. R. Goodman, M. J. Kuhar, S. R. Childers, and S. H. Snyder (1979) Immunohistochemical mapping of enkephalin containing cell bodies, fibers and nerve terminals in the brain stem of the rat. Brain Res. 166: 75-94.

Vanderhaeghen, J. J., F. Lotstra, J. de Mey, and C. Gilles (1980) Immunohistochemical localization of cholecystokinin- and gastrin-like peptides in the brain and hypophysis of the rat. Proc. Natl. Acad. Sci. USA 77: 1190-1194.

Waterhouse, B. D., H. C. Moises, and D. J. Woodward (1980) Noradrenergic modulation of somatosensory cortical neuronal responses to iontophoretically applied putative neurotransmitters. Exp. Neurol. 69: 30-49.

Waterhouse, B. D., H. C. Moises, and D. J. Woodward (1986) Interaction of serotonin with somatosensory cortical neuronal responses to afferent synaptic inputs and putative neurotransmitters. Brain Res. Bull. 17: 507-518. 